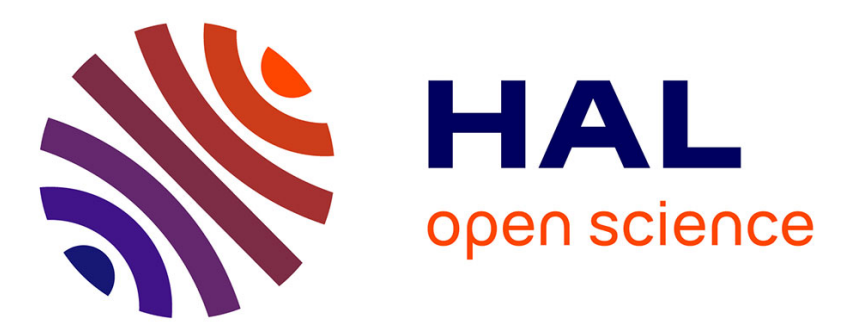

\title{
Inter-hourly variability of total electron content during the quiet condition over Nigeria, within the equatorial ionization anomaly region
}

\author{
T.T. Ayorinde, A. B Rabiu, Christine Amory-Mazaudier
}

\section{- To cite this version:}

T.T. Ayorinde, A. B Rabiu, Christine Amory-Mazaudier. Inter-hourly variability of total electron content during the quiet condition over Nigeria, within the equatorial ionization anomaly region. Journal of Atmospheric and Solar-Terrestrial Physics, 2016, 145, pp.21-33. 10.1016/j.jastp.2016.04.005 . hal01302008

\section{HAL Id: hal-01302008 \\ https://hal.sorbonne-universite.fr/hal-01302008}

Submitted on 13 Apr 2016

HAL is a multi-disciplinary open access archive for the deposit and dissemination of scientific research documents, whether they are published or not. The documents may come from teaching and research institutions in France or abroad, or from public or private research centers.
L'archive ouverte pluridisciplinaire HAL, est destinée au dépôt et à la diffusion de documents scientifiques de niveau recherche, publiés ou non, émanant des établissements d'enseignement et de recherche français ou étrangers, des laboratoires publics ou privés. 


\title{
Inter-hourly Variability of TotalElectron Content during the quiet condition over Nigeria,
}

\section{within the Equatorial Ionization Anomaly region}

\section{T. T. Ayorinde ${ }^{1}$, A. B Rabiu ${ }^{2}$, C. Amory-Mazaudier ${ }^{3,4}$}

${ }^{1}$ Centre for Space Research, North-West University, South Africa.

${ }^{2}$ Centre for Atmospheric Research, National Space Research \& Development Agency, Anyigba, Nigeria

${ }^{3}$ Sorbonne Universités, UPMC Université. Paris 06, UMR 7648, Laboratoire de Physique des Plasmas, F-75005, Paris, France

${ }^{4}$ T/ICT4D, ICTP, Strada Costiera 11, I - 34151 Trieste Italy. toye_tunde@yahoo.co.uk

\begin{abstract}
The inter-hourly variability (IHV) of the Total Electron Content (TEC) over Nigeria during the quiet days (Ap<4) of the year 2013 was examined using ground-based GPS receivers installed at seven (7) different locations across Nigeria by the Nigerian Global Navigation Satellite Systems (GNSS) Reference Network (NIGNET) operated by the office of the surveyor general of Nigeria. Nigeria is a country that lies within equatorial ionospheric anomaly (EIA) region. The IHV was calculated by converting the observed hourly slant TEC (STEC) value into the hourly vertical TEC (VTEC) and the differencing $(\triangle T E C)$ with its corresponding hourly value from the previous day. There is a clear variation which depicts the expected temporal variability. The IHV in TEC in all the stations ranges between 0-20 TECU (TEC Units). The seasonal variation of the IHV of TEC over Nigeria maximizes (5-20 TECU) during Equinoctial months and minimizes (1-10 TECU) during the Solstice months. The IHV of TEC in September equinox period is higher than that of March equinox. Minimum value of IHV ( 7 TECU at equinoxes and $\sim 5$ TECU at Solstice) was recorded at the Office of Surveyor General of the Federation (OSGF) station and the maximum value $(\sim 12$ TECU at equinoxes and $\sim 16$
\end{abstract}


TECU at Solstice) was recorded at the Birni Kebbi FederafPolytechnic (BKFP) station which may be due to the fact that BKFP at $0.72^{\circ}$ dip latitude is closer to the dip equator.

Keywords: Ionosphere, Equatorial Ionospheric Anomaly, Total Electron Content.

\section{Introduction:}

In this paper we analyze the Inter-Hourly Variability (IHV) of the Total Electron Content (TEC) with the Nigerian Global Navigation Satellite Systems (GNSS) Reference Network (NIGNET) of seven GPS stations in the equatorial region, Nigeria. The TEC is the total number of electrons present along a column, with a cross section of $1 \mathrm{~m}^{2}$, path between the satellite and the receiver, with units of TEC (TECU), where 1 TECU $=10^{16}$ electrons $/ \mathrm{m}^{2}$. The variability of ionospheric TEC has a very good practical importance in communication systems, and navigation control application. At the equator, the Earth's magnetic field is horizontal and the ExB drift, related to the Laplace (Lorentz) force, is vertical. During the day, when the zonal electric field is eastward the plasma moves up, and reaches higher altitudes, where the pressure gradient and gravity forces become significant compare to the Laplace (Lorentz) force. At these higher altitudes, the plasma is driven by the ambipolar diffusion along the magnetic field lines. This phenomenon is named the equatorial fountain effect. This fountain effect creates the Equatorial Ionization Anomaly (EIA) composed by a trough of density at the equator and two peaks of density at the geomagnetic latitudes $15^{\circ} \mathrm{N}$ and $15^{\circ} \mathrm{S}$ (Appleton, 1946). This 'fountain effect' is the main driver of the EIA (Martyn, 1955; Townsend et al., 1982; Kelley, 1989; Balan and Bailey, 1995). At the Equator, due also to the horizontal Earth's magnetic field, there is an enhanced ionospheric electric current, the Equatorial Electrojet (EEJ) circulating along the magnetic equator at altitudes around $105 \mathrm{~km}$.

The EIA development depends on a complex coupling of a number of atmospheric processes but foremost it depends on the winds in the upper atmosphere and the Earth's magnetic field at the origin of the ionospheric dynamo electric field. The main following factors affect the EIA's variability with local time, longitude and season; (i) Solar flux, (ii), F-region Neutral Winds, (iii) Quietest and disturbed Magnetic Periods etc. (i) The TEC is strongly related to the solar flux, and as a 
consequence the solar flux variability is actor of variability of the TEC. (ii) At the equator, during magnetic quiet period, the EIA is first produced by the ExB drift which moves up the plasma. This electric field is mainly caused by dynamo action of the neutral wind. The neutral winds have seasonal variation related to the seasonal behavior of the main circulation and atmospheric tides; as a consequence the variability of neutral winds and electric field can explain the variability of the TEC.(iii) During magnetic disturbed periods, the influence of the prompt penetration of the magnetospheric electric field convection (Vasyliunas, 1970) as well as the ionospheric disturbance dynamo (Blanc and Richmond, 1980) modify the equatorial electric field and neutral wind; as a consequence the variability of the neutral winds and electric fields during a magnetic disturbed periods can explain variability in the TEC. The study of the variability of ionospheric parameters is of a great scientific interest in understanding the causative mechanism and a great importance in assessing prediction capabilities; these predictions can be used for various radio communication applications and planning with positioning Global Navigation Satellite Systems (GNSS). Many studies were made in the Asian and American sectors on equatorial aeronomy (EIA, EEJ) (e.g., Kelley, 2009, and references therein). In Africa, the development of studies on TEC started with international projects like the International Heliophysical Year (IHY/2005-2009), (http://www.ihy2007), and the International Space Weather Initiative (ISWI/2010-2012) (http://www.iswi-secretariat.org). In the framework of these projects a larger number of GPS stations were deployed all over Africa, and this allowed the development of ionospheric research in Africa. Many studies were made using GPS derived ionospheric data (Obrou et al., 2009; Ouattara et al., 2012; Bolaji et al., 2012; Bolaji et al., 2013; Oladipo et al., 2014; Bolaji et al., 2015), on the solar cycle and the seasonal behavior of TEC (Moeketsi et al., 2007; Ackah et al., 2011; Zoundi et al., 2012; Shimeis et al., 2014), on magnetic storms (Shimeis et al., 2012; Adeniyi et al., 2014; De Abreu et al., 2014; Shimeis et al., 2015; Azzouzi et al., 2015). This paper is the first paper in Africa devoted to the IHV of TEC. This present work considered the difference between the hourly values of TEC from one day to the corresponding value at the same LT hour on the next day as IHV. The paper thus 
set to investigate the transient and latitudinal IHV of TEC at seven (7) GNSS equatorial stations in Nigeria under quiet condition. The rest of this paper is organized as follows: section 2 describes the data set source and method analysis; the results are given in section 3; while discussion and conclusions separately in sections 4 and 5 respectively.

\section{Data Analysis}

The data used for this paper was obtained from the ground-based GPS receiver stations of the Nigerian GNSS Reference Network (NIGNET) equipment operated by the Office of the Surveyor General of the Federation (OSGoF) Nigeria for the year 2013. The 7 GPS Continuously Operating Reference Stations (CORS) are distributed across Nigeria and the selected stations with their geographic and the geomagnetic coordinates are shown in Table 1 and Figure 1. Only TEC obtained on the magnetically quiet days $(\mathrm{Ap}<4)$ were utilized in this paper. The magnetically quiet days engaged in this study were obtained from the lists of the international quietest days (IQDs) presented

by the World Data Center for geomagnetism (WDC) and is available at http//:www.wdc.kugi.kyoto-u.ac.jp/. Five IQDs were identified per month and for the period when the data were available. The list of the days engaged in this research is presented on Table 2.

TEC is thus defined by Abdullah et al., (2009), as:

$$
T E C=\int_{R}^{S} n_{e}(l) d l
$$

Where $n_{e}(l)$ is the variable electron density along the signal path and the integration is along the signal path from the satellite to the receiver (Pratap and Enge 2006).

The IHV at hour ' $t$ ' was obtained by subtracting TEC at the hour ' $t$ ' on a particular day from its corresponding value on the previous day. Thus IHV of TEC ( $\triangle \mathrm{TEC})$ is given as;

$\Delta T E C_{(t)}=T E C_{(t) i}-T E C_{(t) i-1}$

Where: $\mathrm{t}$ is the local time,

$\mathrm{TEC}_{(\mathrm{t})}$ is the TEC at local time,

$\operatorname{TEC}_{(t) i}$ is the TEC at a particular local time " $t$ " on day " $i$ ", 


\section{$T E C_{(t) i-1}$ is the TEC at same particular local time " $p$ " on the previous day "i-1".}

The mean monthly hourly values of the IHV are obtained by estimating the average magnitudes of the successive differences $\left(\Delta T E C_{(t)}\right)$ in a particular hour for a month. This is the same as Sequential Variability defined by Rabiu (1992), Onwumechili (1997), and Okeke et al. (1998).

$I H V_{t}=\frac{1}{n} \sum_{i=1}^{n} \Delta T E C_{(t)}$

where $\mathrm{i}=1,2,3$ $\mathrm{n}$ and $\mathrm{n}$ is the number of values in the batch in a particular month. The above methodology gives the same result with the result of standard deviation of hourly $T E C_{(t)}$, in the quiet days engaged in this study.

$$
\begin{gathered}
\text { Standard Deviation }\left(\sigma_{t}\right)=\sqrt{\frac{1}{n-1} \sum_{i=1}^{n}\left(T E C_{(t) i}-\mu\right)^{2}} \\
\mu=\frac{1}{n} \sum_{\mathrm{i}=1}^{\mathrm{n}} \Delta \operatorname{TEC}_{(\mathrm{t})}
\end{gathered}
$$

where $i=1,2,3 \ldots \ldots \ldots \ldots . n$ and $n$ is the number of quiet days in a month, is the TEC values in the quiet days at every hour in a month, and is the mean of TEC values at a particular hour " $t$ ".

The solar indices (Sunspot and the Solar Flux $F_{10.7 \mathrm{~cm}}$ ) were also engaged in this research. These are obtained from the OMNIWeb Data Explorer and is available at http://omniweb.gsfc.nasa.gov/form/dx1.html

Figures 2 and 3 show the variation of the mean monthly hourly values of IHV of TEC for all the stations for the year 2013. The daytime averages of IHV of TEC were obtained by averaging the hourly IHV of TEC between the hours of $0700 \mathrm{hrs}$ and $1800 \mathrm{hrs}$ while the night-time averages of IHV of TEC were obtained by averaging the hourly IHV of TEC between the hours of $1900 \mathrm{hrs}$ and 0600 hrs through 2400 hrs over a particular month. Variations of the daytime and night-time IHV of TEC for all the stations are shown in figure 4. The seasonal means of the hourly IHV of TEC were evaluated by averaging the mean monthly values of the IHV of TEC in a particular season viz. DSeason (December, November, January and February), J-Season (May, June, July, August), MarchEquinox (March, April), September-Equinox (September, October); the variations of these for all the 
stations are shown in figure 5. The plot of the spatial variation of the IHV of TEC at sunrise (0700 hrs), at daily peak (1400 hrs), and at sunset (2100 hrs) are shown in figure 6.

\section{Results and discussion}

\section{Diurnal variation the inter-hourly variability of TEC}

Figure 2 presents the mass plots of the diurnal variation of monthly mean of TEC for all the stations used in this research for quiet geomagnetic conditions. Generally it is observed that the diurnal variation of TEC in all the stations experiences an increase from about sunrise to a maximum around afternoon and then falls to a minimum at sunset. The diurnal variation of TEC over Nigeria exhibits the characteristics of a typical equatorial station in which the TEC variation is minimum at pre-dawn and increase with the time of the day attaining a maximum in the afternoon and a decrease before sunset. However, the spread in TEC at the solstice months are minimum, whereas at equinoctial months, the spread in TEC is maximum in all the stations. The TEC values $(\sim 5$ TECU) are a bit higher in FUTY (dip latitude: $-1.33^{\circ}$ ), ABUZ (dip latitude: - 0.62 ${ }^{\circ}$ ), and BKFP (dip latitude: $\left.0.72^{\circ}\right)$ stations than others. In all these plots the diurnal variation shows a sharp and short-lived day minimum ( $\sim 5$ TECU) in TEC occurring around 05:00 to 06:00 LT and an early (12:00 to 14:00 LT) day maximum in TEC occurs in all the stations which shows that the ionization of Nigeria ionosphere may be not uniform and this could probably made the internal dynamics of its ionosphere to experience non-uniformity.

This daytime peak is in agreement with the result of Alex and Rastogi (1989) for TEC at some Indian equatorial stations. The daytime maximum was relatively broad in most of the months especially in the equinoctial months and for a longer period. One can infer that the equivalent variability in strength of the EIA and EEJ, already identified by Bagiya et al. (2009) and Aravindan and Iyer (1992) are responsible for the daytime peak of TEC. Bagiya et al., (2009) mentioned that 'EEJ controls the strength and latitudinal extent of equatorial ionization anomaly'. Bagiya et al., (2009) reported that 'On strong EEJ days, the EIA also intensifies transferring more plasma to the crest 
region and on the counter EEJ day, the anomaly is suppressed and TEC shows low values near the crest region. Results of Bagiya et al., (2009) further suggested that EEJ fully control the EIA, and hence the distribution of F-layer plasma in the low latitude ionosphere.

Figures 3 and 4 respectively present the diurnal variation of monthly mean of the IHV of TEC and the contour plot of monthly mean of the IHV of TEC for all the stations used in this research for quiet geomagnetic condition. It is observed that the IHV of TEC in all the stations experience variations in all the months. The months of February and January experience little or no variability in all the stations and the June solstice months (May, June, July, Aug) show significant variability at postsunset and in the post-midnight. The sunset variability could be as a result of day-to-day variability in the occurrence of Rayleigh-Taylor (RT) plasma instability mechanism that occurs at the post sunset periods. At equatorial latitudes, the Rayleigh-Taylor plasma instability is triggered by the PreReversal Enhancement of the eastward electric field (PRE). At the time of the PRE, the eastward electric field moves up quickly the ionospheric layers, and creates large gradient of electron density and conditions for the development of the R-T instability [e.g., Kelley, 2009, and references therein]. This instability at the bottom-side of F-region near the magnetic equator gives rise to TEC depletions and thereby causing plasma bubble in the EIA region. The variability during night hours may also be as a result of the thermospheric neutral wind and temperature due to the cooling at night (Dabas et al., 1984; Prasad and Rama Rao, 1993; Sharma et al., 2005; Dabas et al., 2006; and Chandra et al. 2009). The post-midnight IHV may be as a result the F-region dynamo processes. It is also observed that in equinoctial months (March, April, September, and October) in all the stations, there is significant increase in the IHV in the daytime especially when TEC is at peak which may be as a result of the zenith angle of the Sun being directly overhead $\left(\sim 90^{\circ}\right)$ the earth and the EIA regions experience more ionization. Prominent secondary peak after sunset, known as post-sunset secondary maximum (PSSM), is also noticed in all the stations. PSSM usually occurred in the evening before midnight and were more pronounced during equinoxes. Wan Hassan et al. (2001) ascribed the PSSM to the irregularity developed by Raleigh-Taylor instability due to the influence of gravitational, 
electric and magnetic fields during high solar activity. Darg et al. (1977) explained the PSSM in terms of the ExB drift from the equatorial anomaly Region.

The day-to-day (inter-hourly) variations of TEC has been be accredited to the changes in Solar activity and other associated changes in the intensity of the incoming radiations and the zenith angle at which they impinged on the Earth's atmosphere as well as the contributions by the various parameters like EUV flux (Kane, 1982; Mendillo et al., 1980; Modi and Iyer, 1989), EEJ strength (Rastogi 1990), meridional neutral winds (Kelley, 2009; Rama Rao et al., 2010) and local atmospheric conditions in the thermosphere.

The flow of plasma in the EIA may also play a significant role in the IHV of TEC in the region. Zhao et al. (2008) suggests that studying very large day-to-day variability under quiet geomagnetic conditions could reveal more about the coupling processes between the ionosphere and lower atmosphere.

Figures 5 and 6 illustrate the IHV in the daytime and that of the night-time of the TEC for all the stations and the seasonal variation of the IHV of TEC for daytime and night-time for all the stations. It is observed that the IHV of TEC over Nigeria is more prominent in the daytime than the night-time most especially in the March equinox, which may be due to the high solar radiation in the daytime and EEJ strength associated with the EIA (Rastogi and Rajaram 1971), meridional neutral winds (Kelley, 2009; Rama Rao et al., 2010) and local atmospheric conditions in the thermosphere. It was believed that the extent of the anomaly in the EIA region affects the EEJ strength (Sethia et al., 1980, Balan and Iyer 1983, Dabas et al., 1984, Rama Rao et al., 2006a, b). It is also observed that the night-time variability is higher than the daytime in the months of September (FUTY OSGF ULAG UNEC), October (CLBR, OSGF, ULAG, UNEC), November (BKFP, CLBR, OSGF, ULAG), and December (ABUZ, BKFP). The variability during daytime could be attributed to electric field strength that gives rise to vertical drift and consequent ionization anomaly, while the variability during night hours may be due to the Rayleigh-Taylor plasma instability, the variability in thermospheric neutral winds and temperature (Chandra et al., 2009). Rishbeth and Mendillo (2001). 


\section{The Seasonal inter-hourly Variability of TEC.}

Figure 7 shows the variation of the seasonal IHV of the TEC at all the stations used in this research. It was noted that the variability is highest in the September equinox of both years and minimizes at June solstice, this result is in good agreement with the result of Kitsadawanich et al. (1999), Bagiya et al. (2009), and Chauhan et al. (2011). The seasonal plot of the nighttime and daytime of the interhour variability shows that the June solstice months has the lowest variability in all the stations $(\sim 5$ TECU). It was also observed that the minimum value ( 7 TECU at equinoxes and $\sim 5$ TECU at June Solstice) was recorded in OSGF station and the maximum value ( 12 at equinoxes and $\sim 16$ at June Solstice) was recorded in BKFP station. This result links the work of Soicher and Gorman (1985) who noted that the winter and summer data indicate that during non-magnetically-disturbed periods, the TEC values are at the diurnal peak, exceeding the monthly mean values, which tends to occur on consecutive days, and also during the equinoxes the peak values may occur randomly, and concluded that day-to-day variability of TEC over a place is the most difficult quantity to predict, the results have implications for prediction improvement. But Tsai et al. (2001) suggested that the phenomena could be fully explained by a combined theory of the transequatorial neutral wind, the subsolar point, and the aurora equatorward wind. The result show that TEC variability in September equinox is greater than March equinox and this may be due to the position of locations considered on earth to the Sun at the different equinoxes. In all it shows TEC variability in December solstice is higher than June solstice in all the stations. Considering the magnetic indices Ap and the high TEC variability recorded in March equinox and December solstice in all the stations, the ionospheric dynamics over Nigeria could have played a major role in the IHV of TEC.

\section{Conclusion}

We have analysed the TEC dataset in seven (7) NIGNET GPS stations at different locations across Nigeria in order to investigate the IHV of TEC during the quiet condition over the country. The IHV was calculated by converting the observed hourly slant TEC (STEC) value into the hourly 
vertical TEC (VTEC) and the differencing $(\triangle T E C)$ with its corresponding hourly value from the previous day. It was revealed that the IHV has a diurnal variation which peaks during the daytime between 1400-1600 LT hours for all the months in all the stations. The IHV of TEC for both daytime and Nighttime is more in the march Equinox in all the stations. The seasonal variation of the IHV of TEC over Nigeria maximizes (5-20 TECU) during Equinoctial months and minimizes (1-10 TECU) during the Solstice months. The IHV of TEC in September equinox period is higher than that of March equinox; and Minimum value of IHV ( 7 TECU at equinoxes and 5 TECU at Solstice) was recorded in OSGF station and the maximum value ( 12 TECU at equinoxes and $\sim 16$ TECU at Solstice) was recorded in BKFP station. The IHV of TEC is related to the ExB drift which moves up the plasma at the equatorial anomaly region. Also the variability of neutral winds and electric field, and the F-region dynamo processes can explains the IHV of TEC. The sunset variability of IHV of TEC could be as a result of day-to-day variability in the occurrence of Rayleigh-Taylor (RT) plasma instability mechanism that occurs at the post sunset periods.

\section{Acknowledgements}

We sincerely appreciate the Office of the Surveyor General of the Federation (OSGoF) of Nigeria operating Nigerian GNSS Reference Network (NIGNET) equipment for providing the data used for this research work. We appreciate the Institute of Scientific Research, Boston College, USA for the TEC analysis software. 


\section{ACCEPTED MANUSCRIPT}

\section{References}

Abdullah, M., Zain, A.F.M., Ho Y.H., Abdullah, S., 2009. TEC and Scintillation study of Equatorial Ionosphere: A month campaign over Sipitang and Parit Raja Stations. American Journal of Engineering and Applied Sciences, Malaysia 2, 44-49.

Ackah, J-B, O.K. Obrou, Z. Zaka, M.N. Mene, K. Groves: 2011, Study of equatorial ionospheric scintillations and TEC characteristics at solar minimum using GPS-SCINDA data, Sun and Geospace, 6(1), 23-26.

Adeniyi, J.O., P.H. Doherty, O. Oladipo, O.S. Bolaji. :2014, Magnetic storm effects on the variation of TEC over Ilorin an equatorial station, Radio Sci., 49, doi: 10.1002/2014RS005404.

Alex, S. and Rastogi, R. G., 1989. Day-to-day variability of maximum electron density and Ionospheric electron content at equatorial stations. Indian Journal of Radio and Space Physics $18,99-102$.

Appleton, E.V., 1946. Two Anomalies in the ionosphere. Nature 157, 691.

Azzouzi, I., Y. Migoya-Orué, C. Amory Mazaudier, R. Fleury, S. Radicella, A. Touzani : 2015, Signatures of solar event at middle and low latitudes in the Europe-African sector, during geomagnetic storms, Advances in Space Research, doi:http://dx.doi.org/10.1016/j.asr.2015.06.010

Bagiya, S. M., Joshi, H. P., Iyer, K.N., Aggarwal, M., Ravindran, S., Pathan, B.M., 2009. TEC variations during low solar activity period (2005-2007) near the Equatorial Ionospheric Anomaly Crest Region in India. Annales Geophysicae 27, 1047-1057.

Balan, N. and Bailey, G.J., 1995. Equatorial Plasma fountain and its effects: Possibility of an additional layer. Journal Geophysical Research 100, 421.

Balan, N. and Iyer, K. N., 1983. Equatorial anomaly in Ionospheric total electron content and its relation to dynamo current. Journal of Geophysical Research 88, 10259-10262. 
Blanc, M., A. D. Richmond: 1980, The Ionospheric disturbance dynamo, J. of Geophys. Res., Vol. $85, \mathrm{~N}^{\circ} . \mathrm{A} 4,1669-1686$.

Bolaji, O.S., Adeniyi, J.O., Radicella, S.M. et al. :2012, Variability of total electron content over an equatorial West African Station during low solar activity, Radio Science, Vol 47, Article Number RS 1001.

Bolaji, O.S., Adeniyi, J.O. Adimula, I. et al. : 2013, Total electron content and magnetic field intensity over Ilorin, Nigeria, Journal of Atmospheric and Solar-Terrestrial Physics, Vol. 98, p $1-11$.

Bolaji, O.S., P.A. Izang, O.R. Oladosu, F. Koya, R.S. Fayose, A.B. Rabiu.: 2015, Ionospheric timedelay over Akure using global positioning system observations, Acta Geophys., doi: 10.1515/acgeo-2015-0018.

Chandra, H., Sharma, S., Soe, W A., 2009. Day-to-day variability in the critical frequency of F2 layer over the anomaly crest region, Ahmedabad. Journal Indian Geophysical Union 13, 217-226.

Chauhan, V., Singh, O.P., Singh, B., 2011. Diurnal and seasonal variation of GPS-TEC during a low solar period as observed at a low latitude station Agra. Indian Journal of Radio and Space Physics 40, 26-36.

Dabas, R. S., Bhuyan, P. K., Tyagi, T. R., Bhardwaj, R. K., Lal, J. B., 1984. Day-to-day changes in Ionospheric electron content at low latitudes. Radio Science 19, 749-756.

Dabas, R. S., Sharma, N., Pillai, M. G. K., Gwal, A. K., 2006. Day-to-day variability of equatorial and low latitude F-region ionosphere in the Indian zone. Journal Atmospheric and SolarTerrestrial Physics 68, 1269-1277.

Darg, S.C., Vijajyakumar, P.N., Singh, I., Tyagi, Y.R., Somayajulu, V.V., 1977. Early results of ATS-6 Radio beacon experiment at New Delhi. Indian Journal of Radio and Space Physics 6, 190-196.

De Abreu, A.J., P.R. Fagundes, M. Gende, O.S. Bolaji, R. De Jesus, C. Brunini : 2014, Investigation of ionospheric response to two moderate geomagnetic storms using GPS-TEC measurements 
in the South American and African sectors during the ascending phase of solar cycle 24, Adv.

Space Res., doi: http://dx.doi.org/10.1016/j.asr.2014.02.011.

Kane, R. P., 1975. Day-to-Day Variability of Ionospheric Electron Content at Mid-Latitudes. Journal of Geophysical Research 80, 3091-3099.

Kane, R.P., 1982. Comparison of changes in the Ionospheric total electron content at mid latitude locations few hundred kilometres apart. Annals of Geophysics 38, 145-151.

Kelley, M. C., 2009. The Earth's Ionosphere; Plasma Physics and Electrodynamics. International Geophysics Series. Academic Press Inc. 43.

Kitsadawanich, S., Deecharat, A., Petnim, O., Junkrob, N., Hemmakorn, N., 1999. Seasonal and Day-to-Day Variability of Ionospheric Total Electron Content at Equatorial Zone near solar maximum by using GPS satellites. IEIC Technical Report 99, 49-56.

Martyn, D. F., 1955. Theory of height and ionization density changes at the maximum of a Chapmanlike region, taking account of ion production, decay, diffusion, and total drift. Proceedings Cambridge Conference, Physical Society, London. 254.

Mendillo, M., Lynch, F. X., and Klobuchar, J. A., 1980. Solar-Terrestrial Predictions 4. Edited by: Donneylly, R. F., Space Environment Lab. Boulder, Colorado, USA.

Modi, R. P. and Iyer, K. N., 1989. IEC and slab thickness near the peak of equatorial anomaly during sunspot maximum and minimum. Indian Journal of Radio and Space Physics 18, 23-26.

Moeketsi, D.M., W.L. Combrinck, L.A. McKinnell, M. Fedrizzi: 2007, Mapping GPS-derived ionospheric Total Electron Content over Southern Africa during different epochs of solar cycle 23, Adv. Space Res., 39, 5, 821-829.

Obrou, O.K., Mene, M.N., Kobea, A.T.:2009, Equatorial total electron content (TEC) at low and high solar activity, Advances in Space Research, Vol.43, p 1757-1761.

Okeke, F. N., Onwumechili, C. A., Rabiu, A. B., 1998. Day-to-day variability of geomagnetic hourly amplitudes at low latitudes. Journal of Geophysical International 134, 484-500 
Oladipo, O.A., A. Adeniyi, J.O., Olawepo, A.O. et al., Space weather- the International Journal of Research and Aplications, Vol. 12, Issue: 5, p 300-305.

Onwumechili, C. A., 1997. Equatorial Electrojet. Gordon and Breach Science Publishers, Netherlands.

Ouattara, F., C. Zoundi, R. Fleury : 2012, Comparison between CODG and GPS based TEC observations at Koudougou station in Burkina Faso, Indian Journal of Radio \& Space Physics, Vol 41, 617-623.

Prasad, D.S.V.V.D and Rama Rao, P.V.S., 1993. Day-to-Day Variability of Ionospheric Electron Content over Waltair. Indian Journal of Radio and Space Physics 22, 391-396.

Pratap Misra and Per K Enge 2006. Global Positioning Systems: Signals, Measurements and Performance. Ganga-Jamuna Press. Lincoln, Massachusetts. Second Edition.

Rabiu, A.B., 1992. Day-to-day variability of geomagnetic variations at low latitude observatory of Muntilupa in the Philippines. University of Nigeria, Nsukka.

Rama Rao, P. V. S., Gopi Krishna, S., Niranjan, K., and Prasad, D. S. V. V. D., 2006a. Temporal and spatial variations in TEC using simultaneous measurements from the Indian GPS network of receivers during the low solar activity period of 2004-2005, Ann. Geophys., 24, 3279-3292, 2006, http://www.ann-geophys.net/24/3279/2006/.

Rama Rao, P. V. S., Niranjan, K., Prasad, D. S. V. V. D., Gopi Krishna, S., Uma, G., 2006b. On the validity of the Ionospheric pierce point (IPP) altitude of $350 \mathrm{~km}$ in the Indian equatorial and low latitude sector. Annals of Geophysics 24, 2159-2168.

Rama Rao, P.V.S., Venkatesh K., Prasad, D.S.V.V.D., Niranjan, K. and Prasad, J. V., 2010. On the Variabilities of the Total Electron Content in the Indian Low Latitude. The international Beacon Satellite Symposium BSS2010, Campus Nord UPC, Barcelona.

Rastogi, R.G. and Rajaram, G., 1971. Electrojet effects on the equatorial F-region during magnetically quiet and disturbed days. Indian Journal of Pure and Applied Physics 9, 531536. 
Rastogi, R. G., 1990. Equatorial ionosphere. Indian Journal of Radio and Space Physics 19, 410-423.

Rishbeth, H., Mendillo, M., 2001. Patterns of Ionospheric variability. Journal Atmospheric and SolarTerrestrial Physics 63, 1661-1680.

Sethia, G., Rastogi, R. G., Deshpande, M. R., Chandra, H., 1980. Equatorial electrojet control of the low latitude ionosphere. Journal of Geomagnetism and Geoelectricity 32, 207-216.

Sharma, D. K., Rai, J., Israil, M., Subrahmanyam, P., 2005. Diurnal, seasonal and latitudinal variation of Ionospheric temperatures of the topside F region over Indian region during solar minimum year 1995-96. Journal of Atmosphere and Solar-Terrestrial Physics 67, 269-274.

Shimeis, A., C. Borries, C. Amory-Mazaudier, R. Fleury, A.M. Mahrous, F. Hassan : 2015 , TEC Variations along an East Euro-African Chain during 5 ${ }^{\text {th }}$ April 2010 Geomagnetic Storm, in Space Research,Volume 55, Issue 9, pp 2239-2247.

Shimeis, A., C. Amory-Mazaudier, R .Fleury, A.M. Mahrous, A. F. Hassan : 2014, Transient Variations of Vertical Total Electron Content over Some African Stations from 2002 to 2012, Advances in Space Research 54, 2159-2171.

Shimeis, A., I. Fathy, C. Amory-Mazaudier, R. Fleury, A.M. Mahrous, K. Yumoto, K. Groves' :2012, Signature of the Coronal Hole on near the North Crest Equatorial Anomaly over Egypt during the strong Geomagnetic Storm $5^{\text {th }}$ April 2010, Vol 117, A07309, doi:10.1029/2012JA0117753.

Singh, M. and Gurm, H.S., 1979. Day-to-day variability in TEC of low latitude ionosphere. Indian Journal of Radio and Space Physics 8, 306-309.

Soicher, H. and Gorman, F.J., 1985. Seasonal and day-to-day variability of total electron content at mid-latitudes near solar maximum. Radio Science 20, 383.

Townsend, R. E., Cannata, R. W., Prochaska, R. D., Rattray, G. E., Holbrook, J. C., 1982. Source Book of the Solar-Geophysical Environment. AFGWC/WSE, Offutt AFB, Neb. 374 
Tsai, H. F., Liu, J. Y., Tsai, W. H.,Liu, C. H., Tseng, C.L., and Wu, C. C., 2001. Seasonal variations of the Ionospheric total electron content in Asian equatorial anomaly regions. Journal of Geophysical Research 106(A12), 30363-30369.

Vasyliunas, V. M. ; 1970, Mathematical models of magnetospheric convection and its coupling to the ionosphere, in Particles and Fields in the Magnetosphere, edited by M. McCormac, Springer, New York , pp $60-71$.

Wan Hassan, W. S., Zain, A. F. M., Ramli, A. G., Hwa, H.Y., Abdullah M., 2001. Studies on equatorial total electron content near solar maximum activity from 1998-2000. Paper presented at XXVIIth General Assembly, Union Radio Science Int. Maastricht, Netherlands.

Zhao, B., Wang, M., Yu, T., Wan, W., Lei, J., Liu, L., 2008. Is an unusual large enhancement of Ionospheric electron density linked with the 2008 great Wenchuan earthquake? Journal of Geophysical Research 113, A11304.

Zoundi C., F. Ouattara, R. Fleury, C. Amory-Mazaudier, P. Lassudrie-Duchesne: 2012, Seasonal TEC variability in West Africa Equatorial Anomaly Region, European Journal of Scientific Research, Vol 77, n03, 309-319. 


\section{ACCEPTED MANUSCRIPT}

Figure 1: The geographic distribution of the NIGNET stations.

Figure 2: The monthly diurnal variation of TEC for the magnetic quiet days.

Figure 3: The variation of monthly means of the inter-hourly variability of TEC.

Figure 4: Inter-hourly variability of $T E C$ over Nigeria.

Figure 5: Inter-hourly variability of the mean daytime and mean night-time $T E C$ over Nigeria.

Figure 6: Seasonal variation of the inter-hourly variability of mean $T E C$ over Nigeria.

Figure 7: Seasonal variation of the inter-hourly variability of mean daytime and mean night-time TEC over Nigeria. 
Table 1: List of GNSS stations and their respective coordinates.

\begin{tabular}{|c|c|c|c|c|c|}
\hline STATION & STATION & GEOGRAPI & & GEOMAGNETIC & \\
\hline \multirow[t]{2}{*}{ CODE } & \multirow[t]{2}{*}{ LOCATION } & \multicolumn{2}{|c|}{ COORDINATES } & \multicolumn{2}{|l|}{ COORDINATES } \\
\hline & & $\begin{array}{l}\text { LATITUDE } \\
\text { (degrees) }\end{array}$ & $\begin{array}{l}\text { LONGITUDE } \\
\text { (degrees) }\end{array}$ & $\begin{array}{l}\text { DIP LATITUDE } \\
\text { (degrees) }\end{array}$ & $\begin{array}{l}\text { LONGITUDE } \\
\text { (degrees) }\end{array}$ \\
\hline CLBR & CALABAR & 4.95031 & 8.351 & -4.30 & 80.09 \\
\hline UNEC & ENUGU & 6.42481 & 7.504 & -3.25 & 79.37 \\
\hline ULAG & LAGOS & 6.51733 & 3.397 & -3.03 & 75.45 \\
\hline OSGF & ABUJA & 9.02767 & 7.486 & -1.60 & 79.49 \\
\hline FUTY & YOLA & 9.34975 & 12.49 & -1.33 & 84.31 \\
\hline ABUZ & ZARIA & 11.1517 & 7.6847 & -0.62 & 79.75 \\
\hline BKFP & BIRNI & 12.4685 & 4.292 & 0.72 & 76.62 \\
\hline
\end{tabular}


Table 2: international Quiet Days (IQDs).

\begin{tabular}{|c|c|c|c|c|c|c|c|c|c|c|c|}
\hline Year & Month & Q1 & Ap & Q2 & Ap & Q3 & Ap & Q4 & Ap & Q5 & Ap \\
\hline 2013 & January & 22 & 1 & 1 & 1 & 5 & 2 & 30 & 2 & 24 & 2 \\
\hline 2013 & February & 6 & 1 & 5 & 2 & 24 & 3 & 25 & 3 & 9 & 3 \\
\hline 2013 & March & 8 & 2 & 7 & 2 & 26 & 2 & 25 & 3 & 13 & 3 \\
\hline 2013 & April & 19 & 1 & 8 & 2 & 18 & 2 & 17 & 2 & 21 & 2 \\
\hline 2013 & May & 29 & 1 & 30 & 2 & 11 & 3 & 12 & 3 & 9 & 4 \\
\hline 2013 & June & 16 & 2 & 26 & 2 & 17 & 3 & 13 & 3 & 14 & 3 \\
\hline 2013 & July & 2 & 3 & 3 & 4 & 17 & 4 & & 4 & 21 & 4 \\
\hline 2013 & August & 29 & 2 & 2 & 2 & 7 & 3 & 8 & 3 & 20 & 3 \\
\hline 2013 & September & 28 & 0 & 26 & 1 & 27 & 1 & 15 & 2 & 29 & 1 \\
\hline 2013 & October & 5 & 0 & 28 & 1 & 4 & 1 & 19 & 1 & 21 & 1 \\
\hline 2013 & November & 25 & 0 & 24 & 0 & 21 & 1 & 27 & 1 & 28 & 1 \\
\hline 2013 & December & 2 & 1 & 12 & 1 & 22 & 1 & 26 & 1 & 27 & 2 \\
\hline
\end{tabular}




\section{ACCEPTED MANUSCRIPT}

Figure 1:

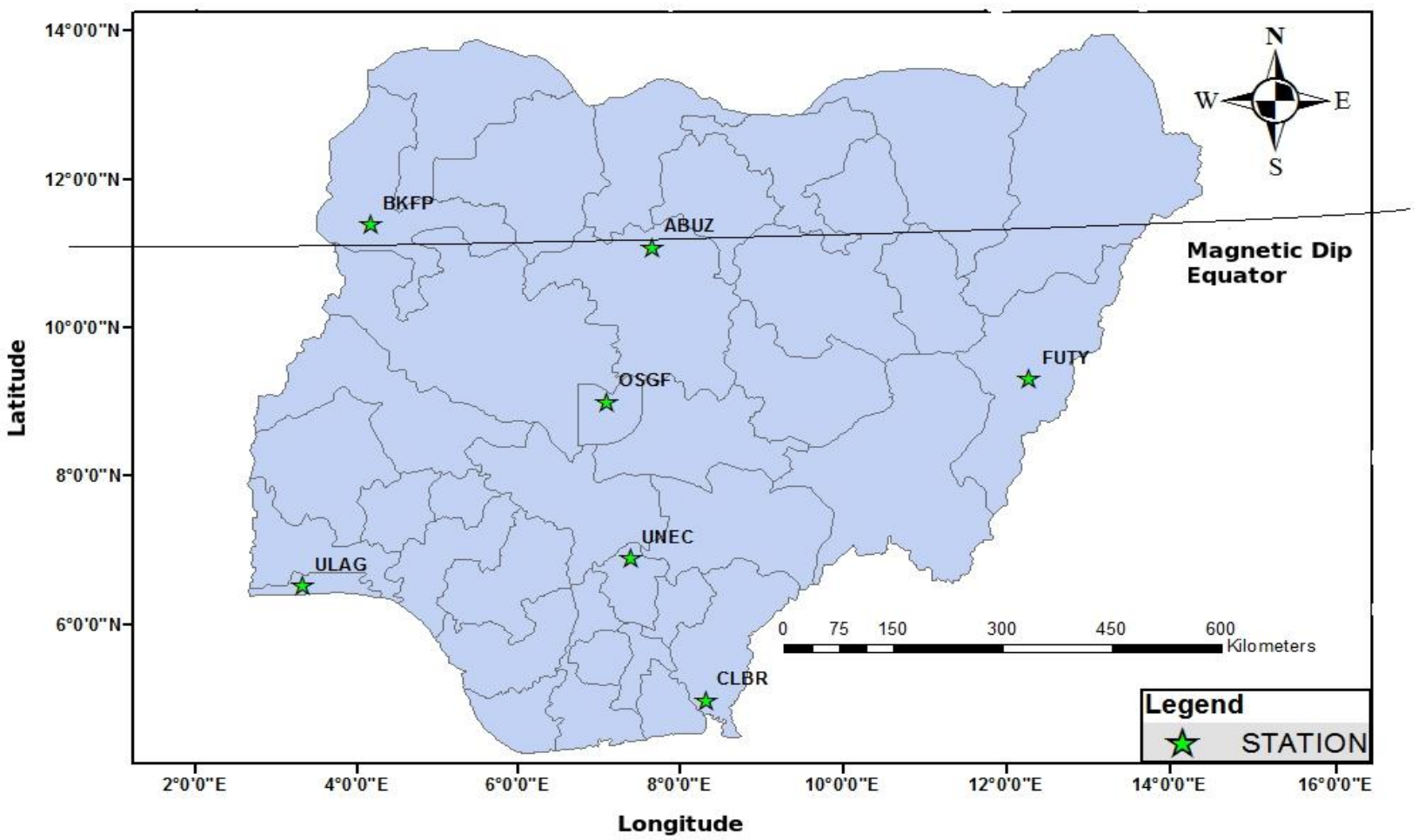

Figure2
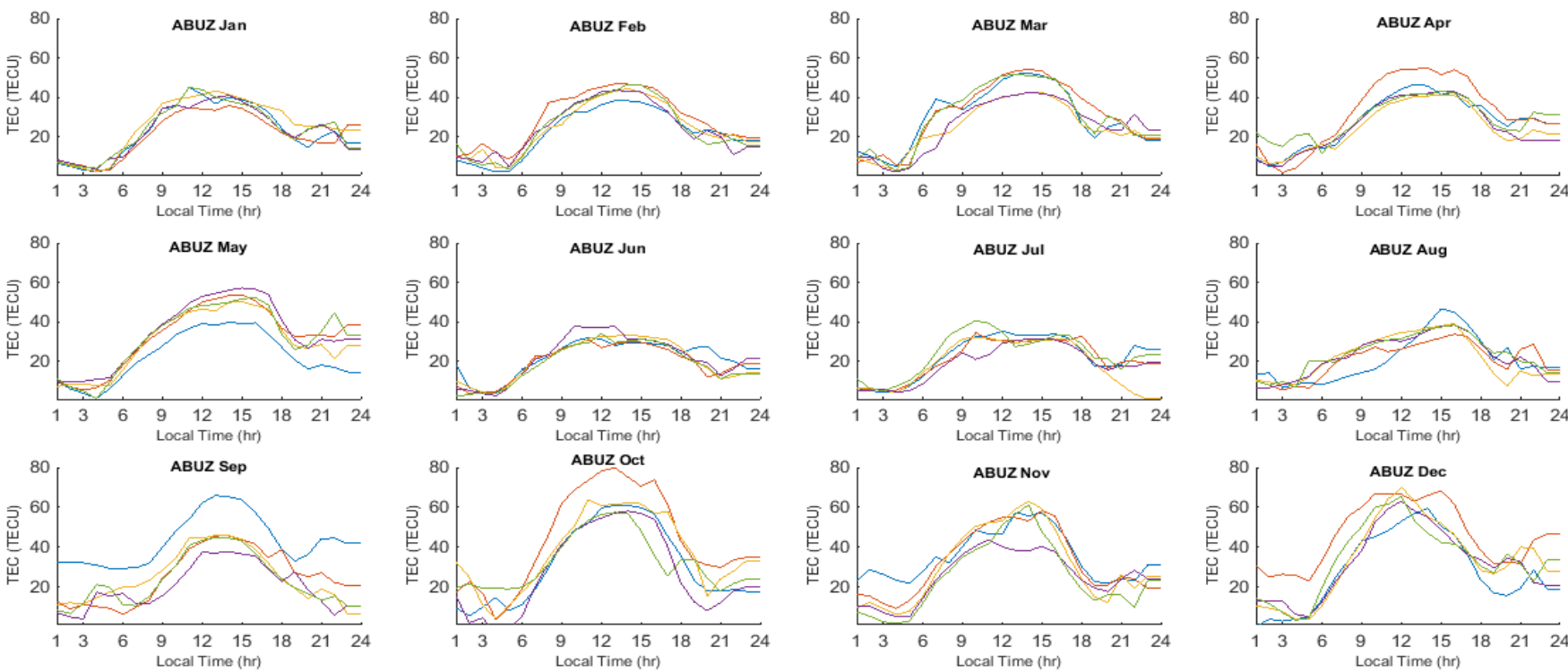

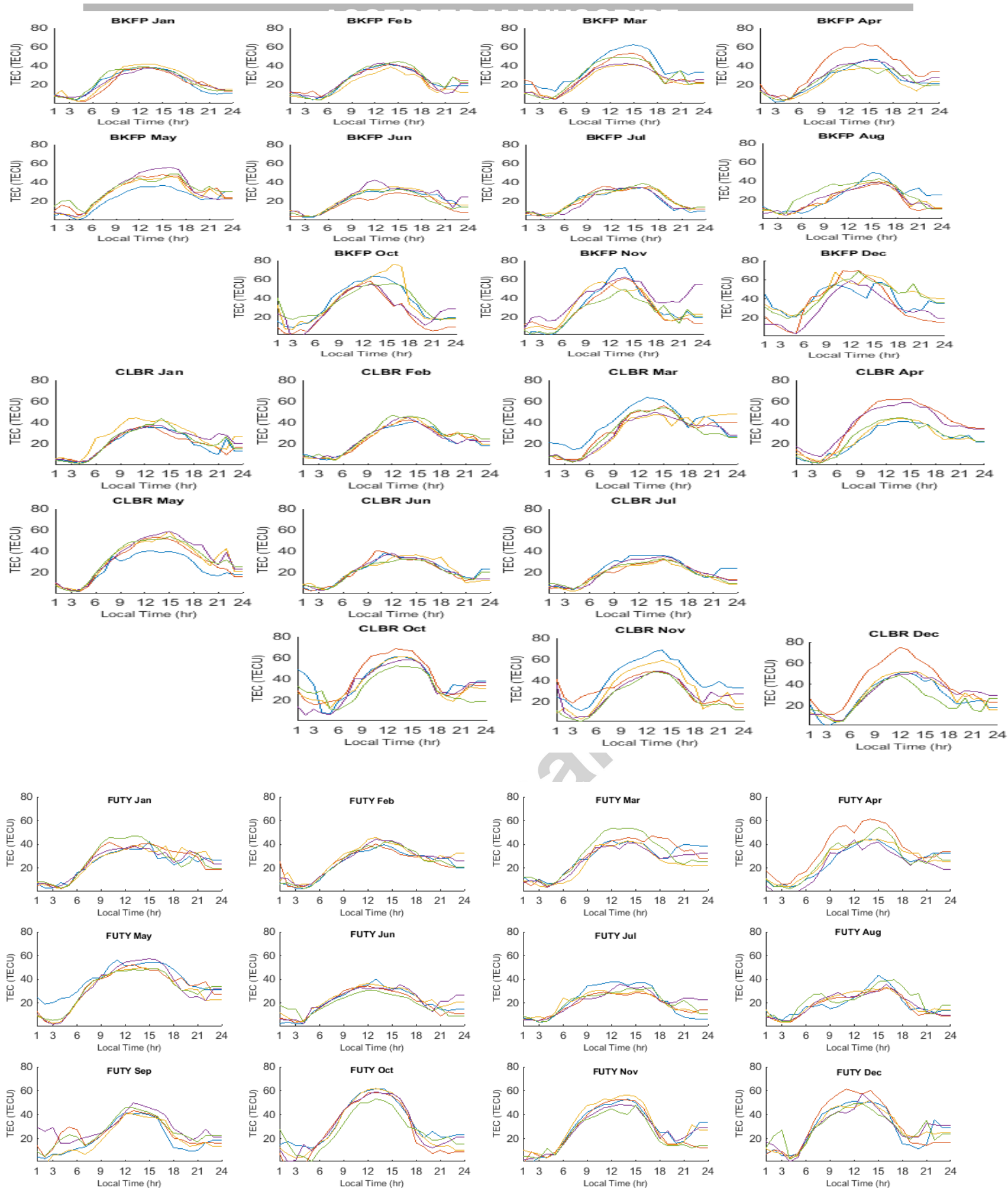

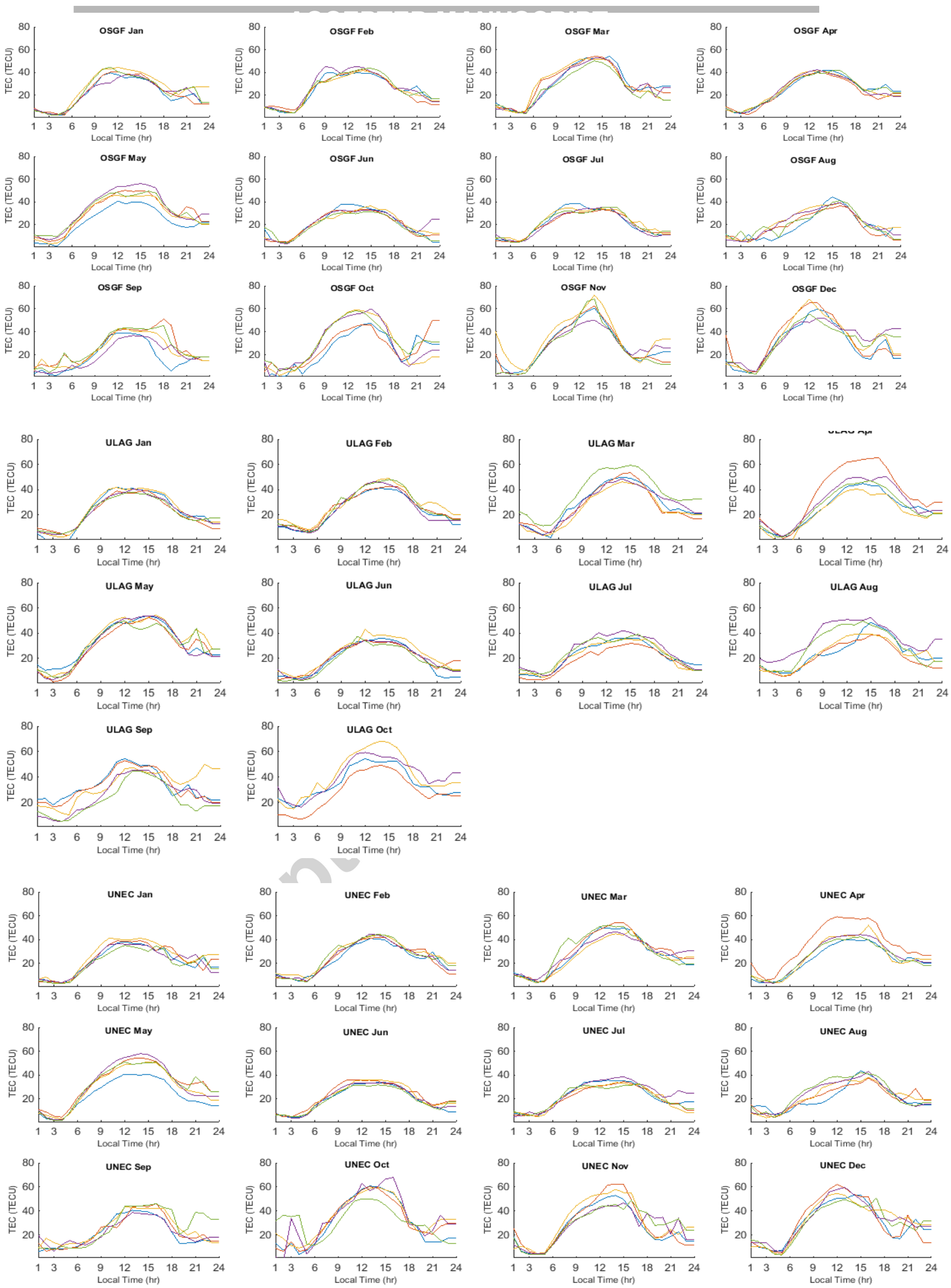
Figure 3:

ACCEPTED MANUSCRIPT
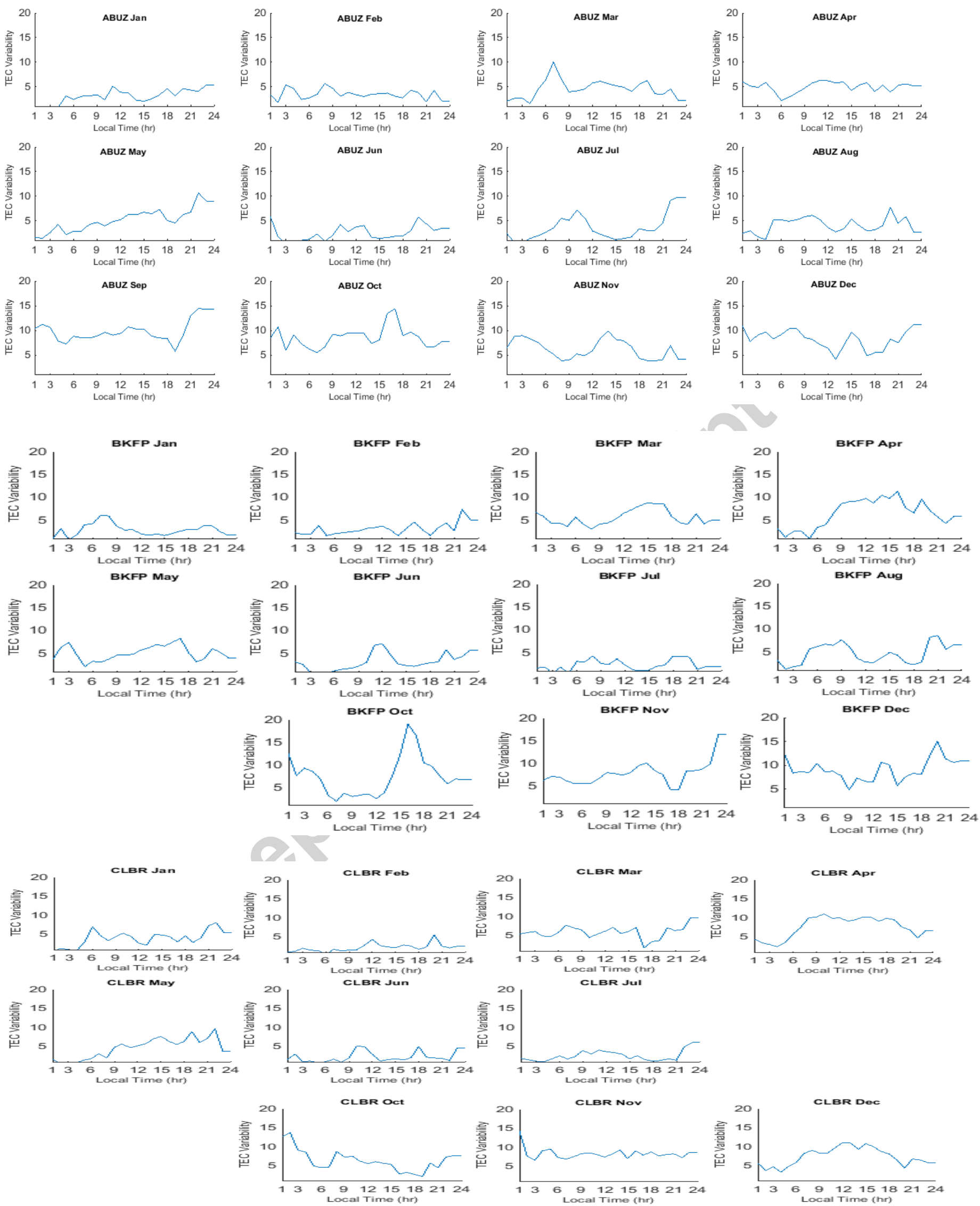

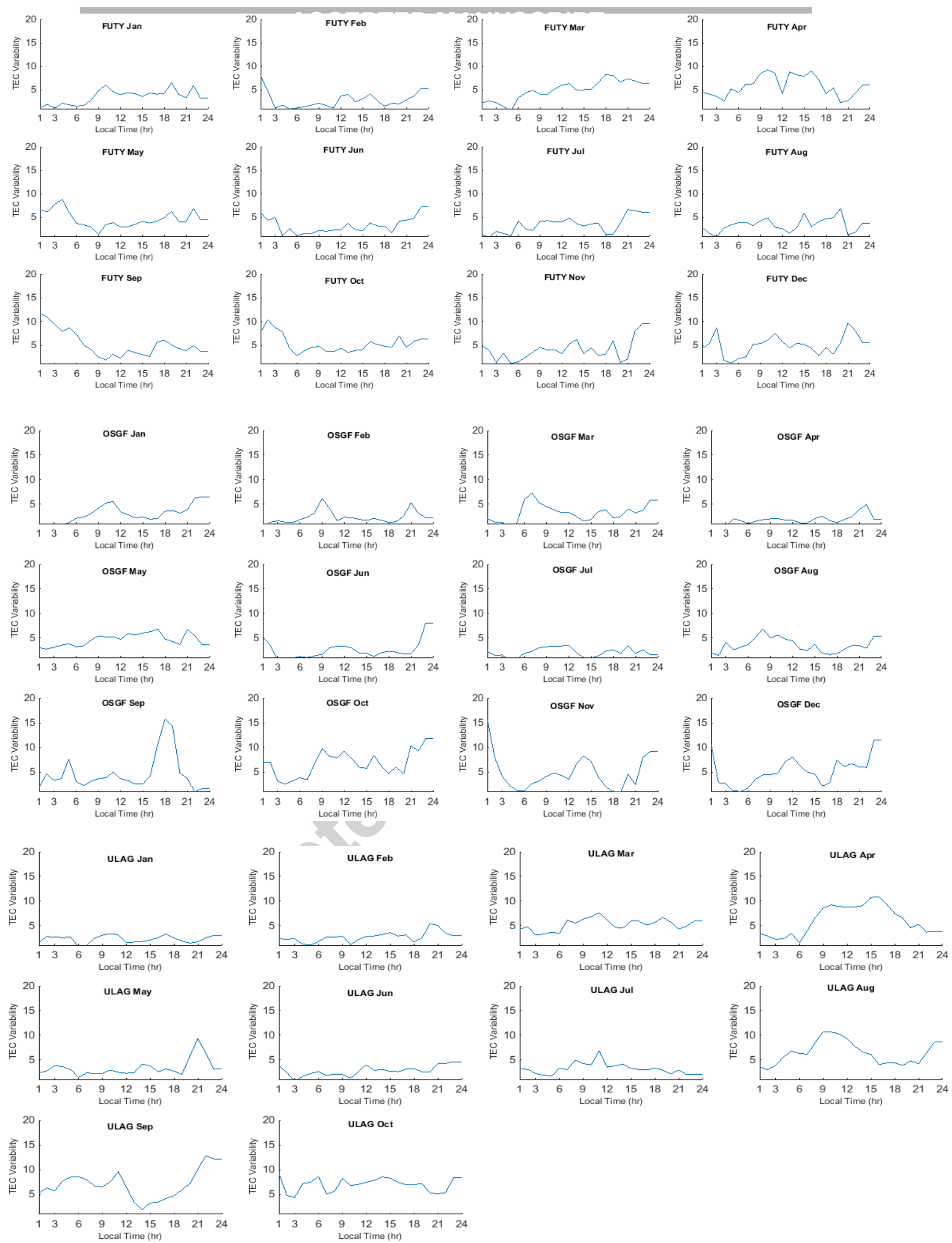

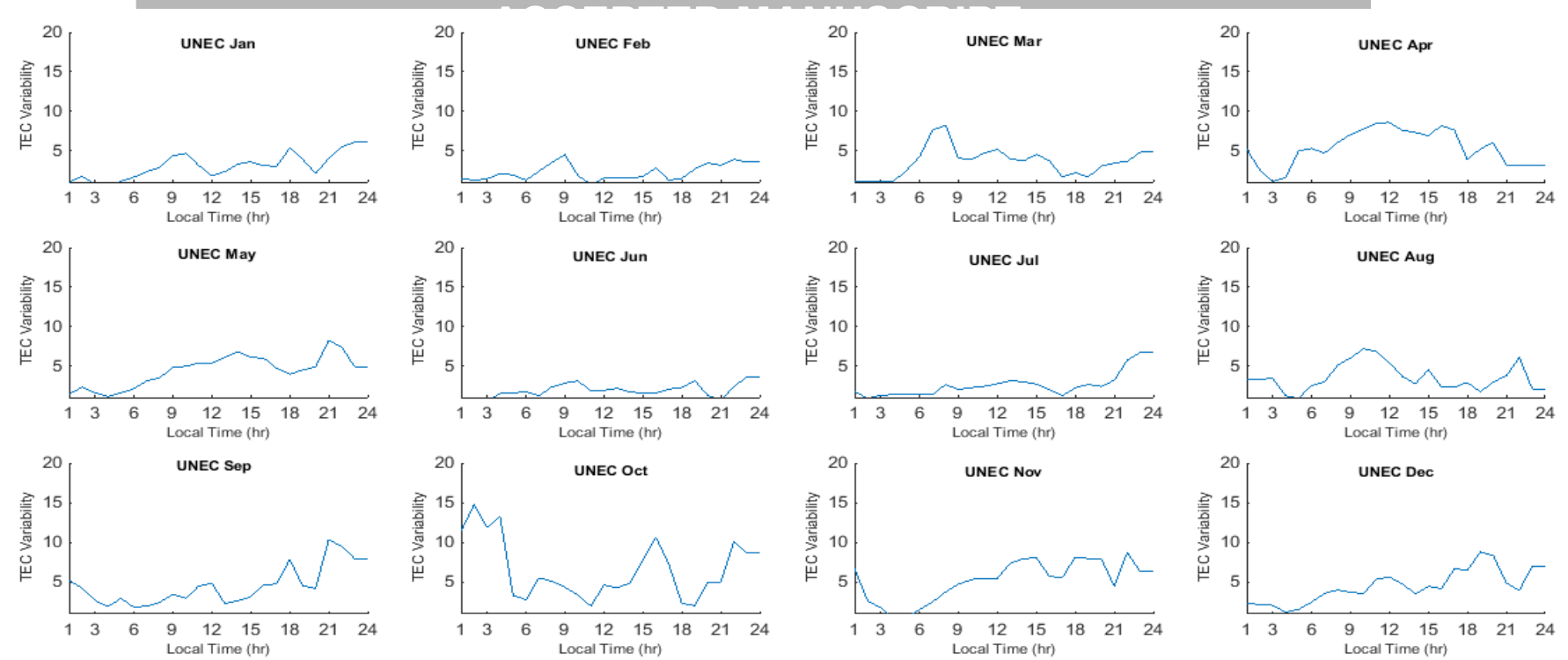

Figure 4:
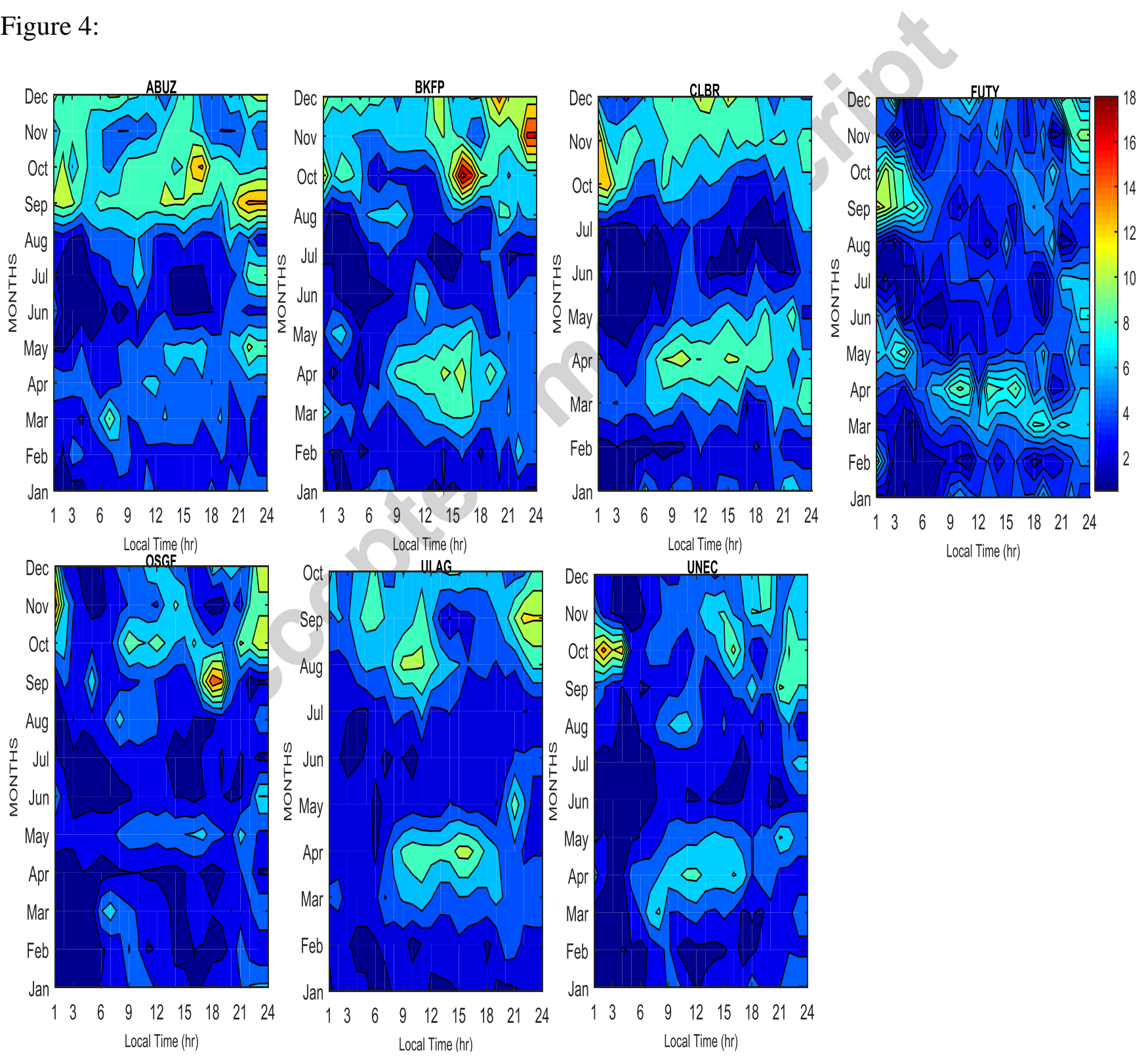
Figure 5:
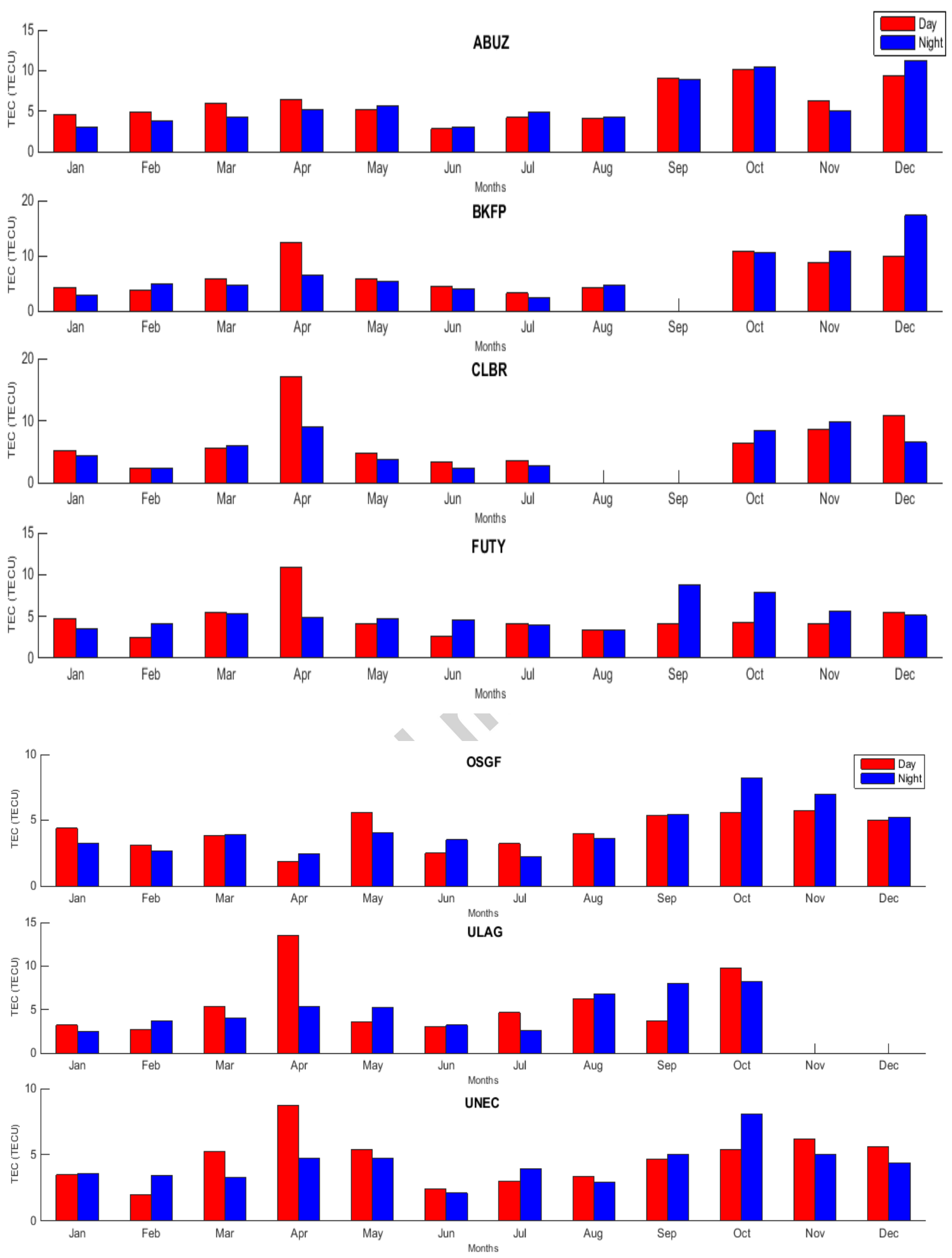

Figure 6: 


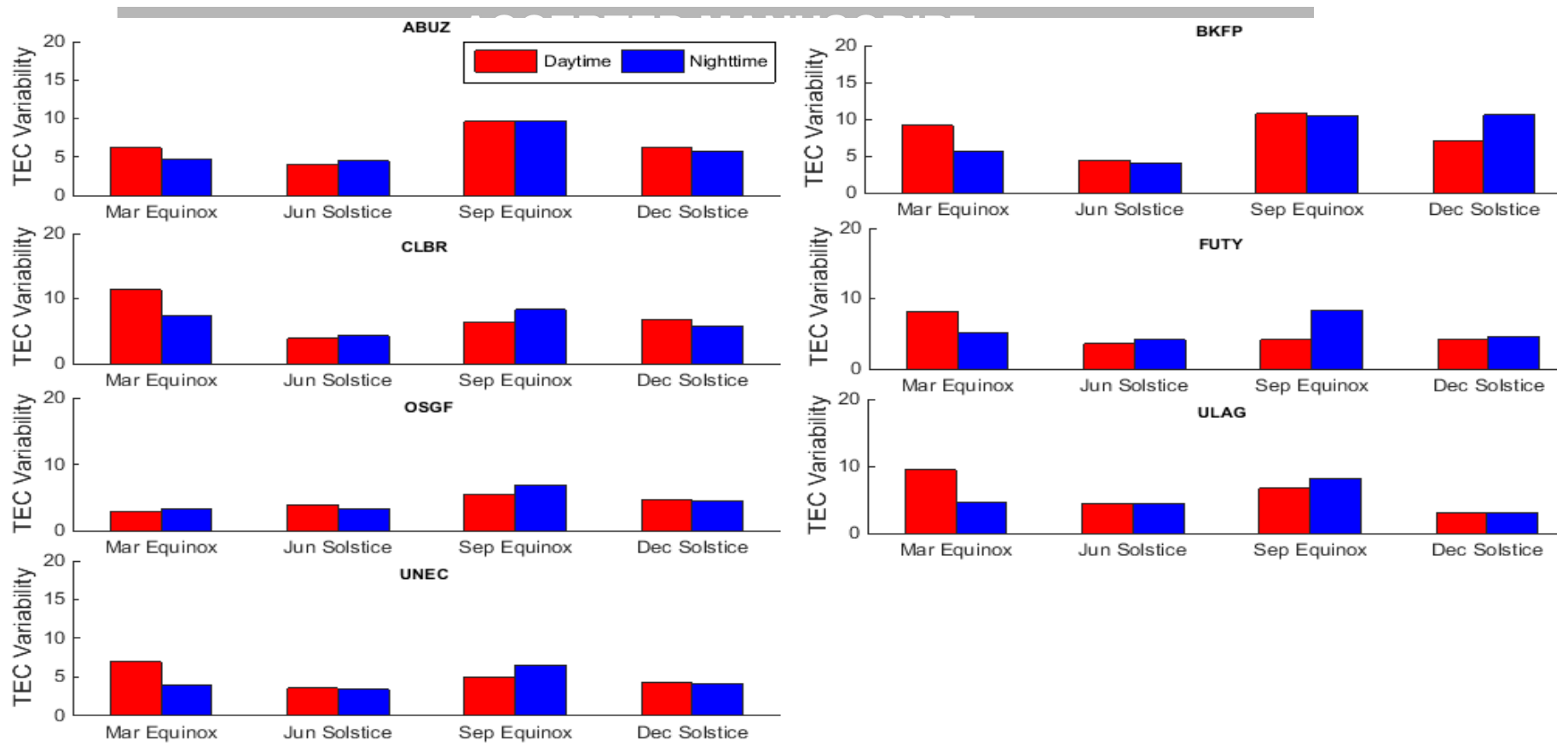

Figure7:

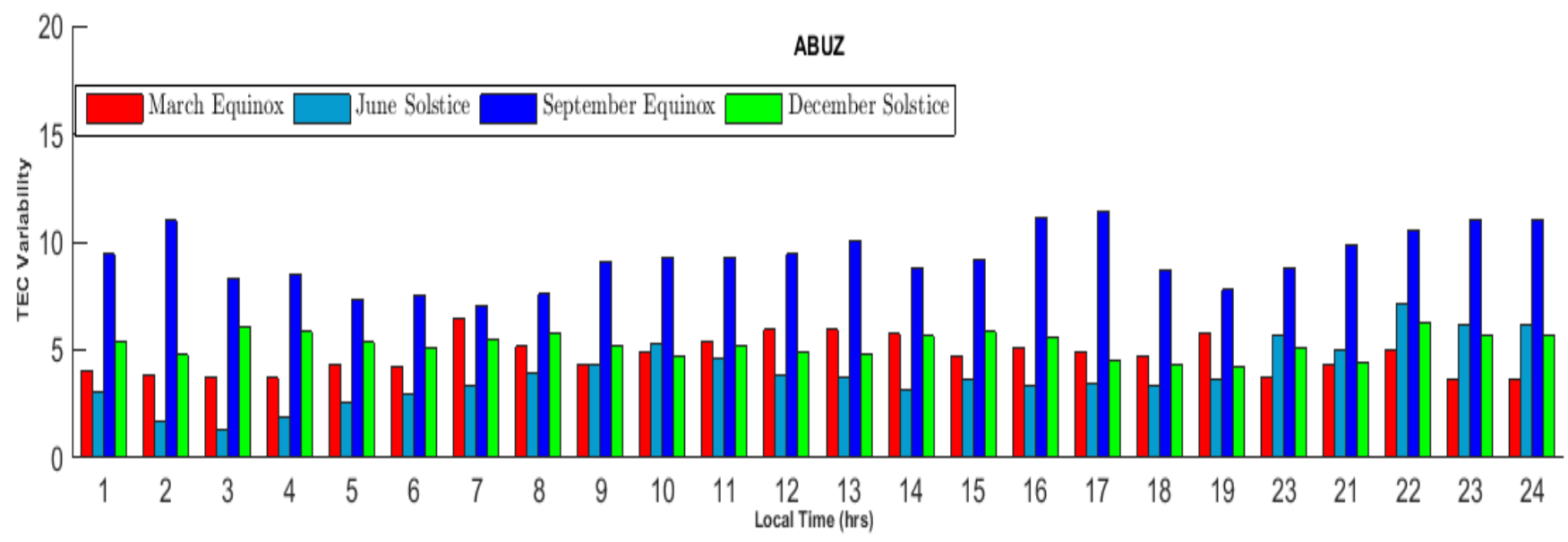



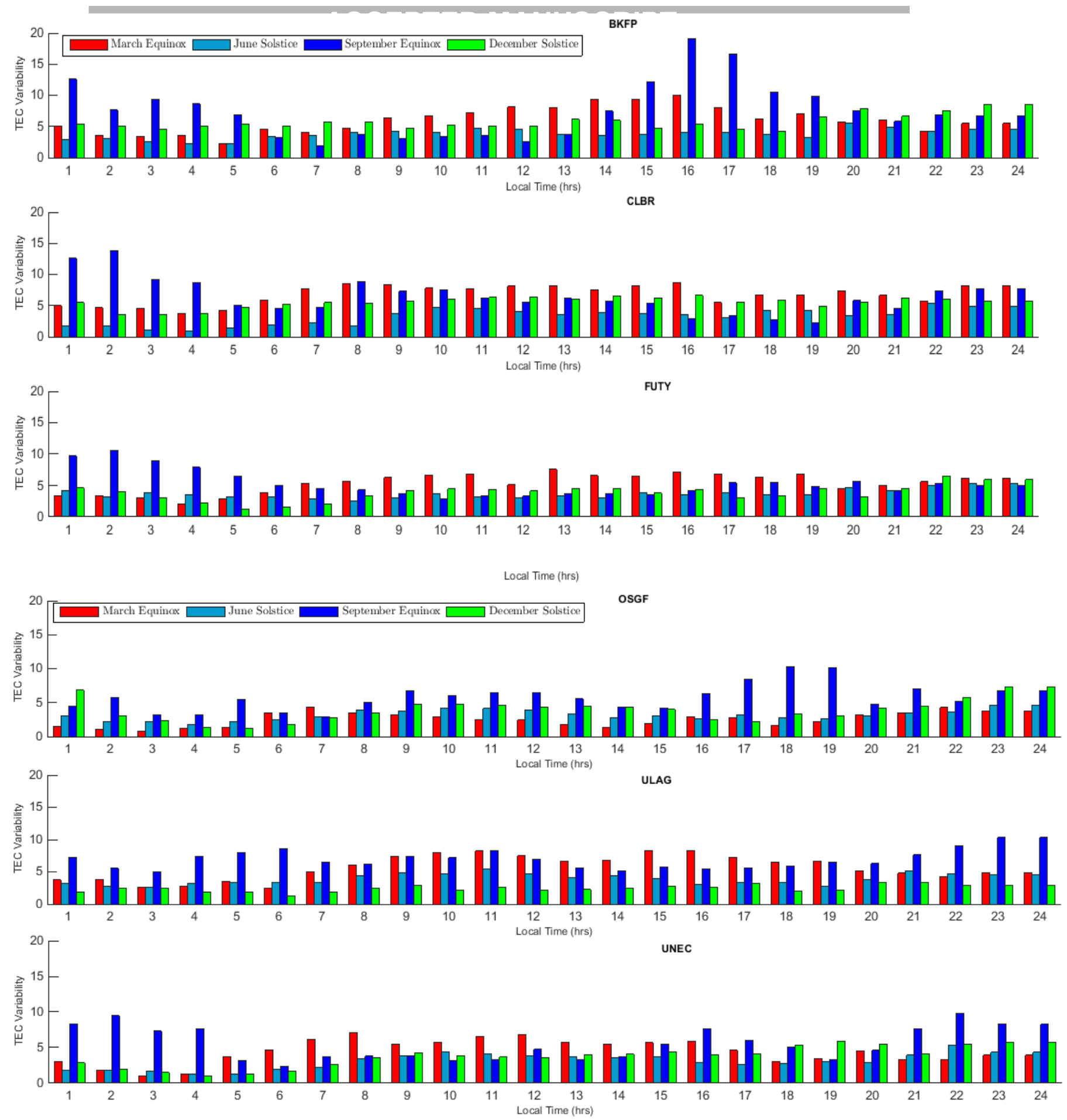